\title{
Commentary: Of costs and compromises
}

\author{
Dawn S. Hui, MD, ${ }^{a}$ and Richard Lee, MD, MBA ${ }^{b}$
}

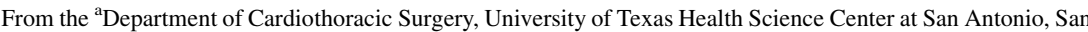
Antonio, Tex; and ${ }^{\mathrm{b}}$ Division of Cardiothoracic Surgery, Department of Surgery, Medical College of Georgia, Augusta University, Augusta, Ga.

Disclosures: Authors have nothing to disclose with regard to commercial support.

Received for publication Sept 1, 2019; revisions received Sept 1, 2019; accepted for publication Sept 3, 2019; available ahead of print Oct 21, 2019.

Address for reprints: Richard Lee, MD, MBA, Department of Surgery, Medical College of Georgia, 1120 15th St, BA-4300, Augusta, GA 30912 (E-mail: richardleemdmba@gmail.com or RICKLEE@augusta.edu).

J Thorac Cardiovasc Surg 2020;159:e63-4

0022-5223/\$36.00

Copyright (C) 2019 by The American Association for Thoracic Surgery

https://doi.org/10.1016/j.jtcvs.2019.09.021
}

The benefits of coronary artery bypass grafting (CABG) are well-known. One paper described it as "the most completely studied operation in the history of surgery." 1 Despite advancements in percutaneous coronary interventions, $\mathrm{CABG}$ is still associated with better survival, lower rates of major cardiovascular events, and less repeat revascularization in a number of cohorts, including multivessel disease, complex lesions, left main disease, and reduced ejection fraction. ${ }^{2-4}$ These remarkable benefits may come at the "cost" of sternotomy and, at times, cardiopulmonary bypass and cardioplegic arrest. Although isolated $\mathrm{CABG}$ is remarkably safe, with short-term mortality being $<2 \%$ at large teaching and urban hospitals internationally, ${ }^{5}$ minimally invasive techniques have been proposed to overcome some of these "costs." In the Journal, Hashimoto and colleagues ${ }^{6}$ report on a recent surgical innovation in coronary revascularization, automated coronary anastomotic devices. The authors cite "lack of familiarity" with devices as the barrier to adoption of totally endoscopic coronary artery bypass (TECAB). Accordingly, their position is that the associated reduction in ischemic time should prompt widespread TECAB practice.

In light of the fact that $\mathrm{CABG}$ remains the preferred operation for many patients, it is incumbent on surgeons to continue to provide durable results that are superior to percutaneous coronary intervention or medical management. The authors describe their early and midterm results as "excellent" and "equivalent to hand-sewn techniques." However, we have several concerns with this statement. First, in their most recent paper, $64 \%$ of patients failed screening or were excluded intraoperatively from device use $(205 / 325){ }^{7}$ Of the remaining 117 , only two-thirds had studies of graft patency. At 12 months, the arterial occlusion rate was $12.8 \%$, vein occlusion rate $16.3 \%$, and left anterior descending graft occlusion rate $9.7 \%$. In their largest study greater patency rates of $96 \%$ were reported, but patency was studied in only $33.7 \%$ of patients $(116 / 344)$, at a rather short follow-up time of 6.5 months. ${ }^{8}$ An earlier study

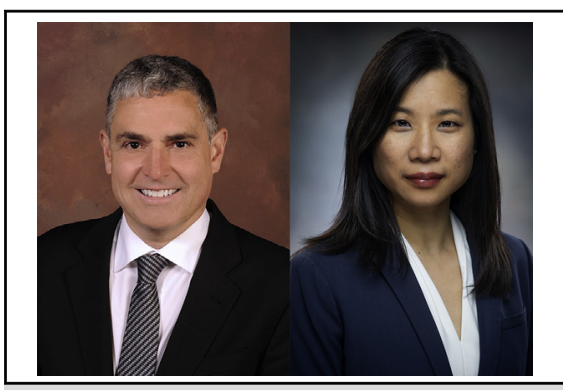

Richard Lee, MD, MBA, and Dawn S. Hui, MD

Central Message

Adoption of innovations in cardiac surgery requires high-quality supporting evidence and during the development period, transparen disclosure to patients regarding the investigational nature.

See Article page e57.

showed similar limitations, with only $56 \%$ patients having patency studies, at a mean of 4 months.

Transparent disclosure to patients regarding risks and unknown durability are mandatory. In the authors' own words from their earlier work, "A significant learning curve is involved and experience with anastomotic devices in the open setting is necessary. Long-term follow-up of graft patency and patient outcomes is warranted." in this manuscript they have reduced the issue of TECAB to mere technicalities, suggesting that surgeons need only a series of "tips and tricks" to adopt TECAB safely. Certainly, innovation in cardiac surgery should be pursued. However, it should maintain the high standards and excellent outcomes of current treatment. Recall the lessons of off-pump CABG, which even in experienced hands has not lived up to its promise. ${ }^{10}$ Further, contrast the evolution of transcatheter aortic valve replacement, which began with prohibitive surgical risk patients who lacked other effective therapeutic options. This approach helped to overcome ethical concerns, by investigating new technology's potential benefits in patients with otherwise-defined poor shortterm outcomes. Approval of transcatheter aortic valve replacement for low-risk patients was contingent on welldesigned, federally regulated clinical trials, and mandatory registry data. Counseling low-risk patients on long-term durability is still a difficult conversation. Hashimoto and colleagues propose an opposite approach; it appears lowrisk patients are placed at risk without clear demonstrated 
benefit and uncertain long-term durability. While the authors' paper provides tools to pursue the safety of TECAB, it does nothing to reassure of its durability. The real barriers to surgeons adopting TECAB are the lack of long-term, high-quality data supporting superiority to conventional CABG.

\section{References}

1. Hawkes AL, Nowak M, Bidstrup B, Speare R. Outcomes of coronary artery bypass graft surgery. Vasc Health Risk Manag. 2006;2:477-84.

2. Mack M, Baumgarten H, Lytle B. Why surgery won the SYNTAX trial and why it matters. J Thorac Cardiovasc Surg. 2016;152:1237-40.

3. Spadaccio C, Benedetto U. Coronary artery bypass grafting (CABG) vs. percutaneous coronary intervention (PCI) in the treatment of multivessel coronary disease: quo vadis? - a review of the evidences on coronary artery disease. Ann Cardiothorac Surg. 2018;7:506-15.

4. Iribarne A, DiScipio AW, Leavitt BJ, Baribeau YR, McCullough JN Weidner PW, et al. Comparative effectiveness of coronary artery bypass grafting versus percutaneous coronary intervention in a real-world surgical treatment for ischemic heart failure trial population. J Thorac Cardiovasc Surg. 2018;156 1410-21.

5. Zheng Z, Zhang H, Yuan X, Rao C, Zhao Y, Wang Y, et al. Comparing outcomes of coronary artery bypass grafting among large teaching and urban hospitals in China and the United States. Circ Cardiovasc Qual Outcomes. 2017;10:e003327.

6. Hashimoto M, Wehman B, Balkhy HH. Robotic totally endoscopic coronary artery bypass: tips and tricks for using an anastomotic device. J Thorac Cardiovasc Surg. 2020;159:e57-60.

7. Balkhy HH, Patel NC, Ramshandani M, Kitahara H, Subramanian VA, Augelli NV, et al. Multicenter assessment of grafts in coronaries: midterm evaluation of the C-Port device (the MAGIC study). Innovations. 2018;13:273-81.

8. Balkhy HH, Nisivaco S, Kitahara H, McCrorey M, Patel B. Robotic multivessel endoscopic coronary bypass: impact of a beating-heart approach with connectors. Ann Thorac Surg. 2019;108:67-73.

9. Balkhy HH, Wann LS, Krienbring D, Arnsdorf SE. Integrating coronary anastomotic connectors and robotics toward a totally endoscopic beating heart approach: review of 120 cases. Ann Thorac Surg. 2011;92:821-7.

10. Chikwe J, Lee T, Itagaki S, Adams DH, Egorova NN. Long-term outcomes after off-pump versus on-pump coronary artery bypass grafting by experienced surgeons. J Am Coll Cardiol. 2018;72:1478-86. 